\title{
Studies on the Interference by Haemoglobin in the Determination of Bilirubin
}

\author{
By Jannie A. van der Woerd-de Lange, W. G. Guder, E. Schleicher, Ingrid Paetzke, Margarete Schleithoff and
} O. H. Wieland

Institut für Klinische Chemie, Städtisches Krankenhaus München-Schwabing

(Received Scptember 2/December 1. 1982)

Dedicated to Professor Dr. H. Begemann on the occasion of his 65th birthday

Summary: Haemoglobin interference in the determination of bilirubin was compared in 7 different methods using the Jendrassik-Grof procedure, the Jendrassik-Grof-Nosslin modification, and the more recent procedures using nitrophenyldiazonium, 2,5-dichlorophenyldiazonium, 2,4-dichloraniline, and a direct reading method. To a variable degree, haemoglobin decreased the apparent absorption of the reaction product in all procedures. The extent of this decrease depended on the reagent used, the wavelength, incubation time, bilirubin concentration and the type of blank used. In an attempt to elucidate the mechanism of interference, haemoglobin was found to destroy the bilirubin diazo-compound whereas haemiglobin was ineffective. Likewise, storage of haemolytic samples for several days led to a disappearance of haemoglobin. $\mathrm{H}_{2} \mathrm{O}_{2}$, which had no effect in the absence of haemoglobin, potentiated the action of haemoglobin on diazobilirubin coupling.

From our observations it can be concluded that haemoglobin disturbs the diazo-bilirubin reaction by a dual mechanism. $\mathrm{H}_{2} \mathrm{O}_{2}$, formed from oxyhaemoglobin by autoxidation, destroys the diazo bilirubin colour. In accordance with this explanation, potassium iodide stabilized the diazo compound against the peroxidative effect of oxyhaemoglobin; stabilization was not effective with superoxide dismutase, mannitol or ascorbate.

\section{Studien zur Störung der Bilirubinbestimmung durch Hämoglobin}

Zusammenfassung: Die Störung der Bilirubinbestimmung durch Hämoglobin wurde durch Vergleich 7 verschiedener Verfahren untersucht. Diese umfassen die Jendrassik-Grof-Methode, die Modifikation nach Jendrassik-Grof-Nosslin sowie die neueren Verfahren mit Nitrophenyldiazonium, 2,5-Dichlorophenyldiazonium, 2,4-Dichloroanilin, sowie eine direkt-photometrische Methode. Hämoglobin verminderte die Absorption des Reaktionsprodukts bei allen Verfahren, jedoch in verschiedenem Maße. Das Ausmaß der Störung hängt nicht nur vom Reagenz ab, sondern auch von der verwendeten Wellenlänge, der Inkubationszeit, der Bilirubinkonzentration und der Art der Leerwertbildung.

Beim Versuch, den Mechanismus der Störung zu erhellen, fanden wir, daß Hämoglobin den Diazobilirubinkomplex zerstörte. Hämiglobin hatte dagegen keinen Einfluß. Ebenso blieb die Störung aus, wenn man hämolytische Proben über Tage lagerte. $\mathrm{H}_{2} \mathrm{O}_{2}$, das in Abwesenheit von Hämoglobin keinen Effekt auf die Diazoreaktion hatte, potenzierte die Wirkung des Hämoglobins auf die Diazobilirubinkopplungsreaktion.

Aus den Ergebnissen kann geschlossen werden, daß Hämoglobin auf zweifache Weise die Diazobilirubinreaktion stört: Aus Oxýhämoglobin gebildetes $\mathrm{H}_{2} \mathrm{O}_{2}$ und die peroxidative Wirkung zerstören offensichtlich den Diazobilirubinkomplex. Im Einklang mit dieser Vorstellung zeigte Kaliumiodid, nicht aber Superoxiddismutase, Mannit oder Ascorbat eine stabilisierende Wirkung auf den Diazokomplex gegen die peroxidative Wirkung des Oxyhämoglobins. 


\section{Introduction}

Nearly seventy years ago. Hijmans van den Bergh (1) introduced the diazo coupling method for bilirubin determination. Twenty-five years later, Malloy \& Evelyn (2) and Jendrassik \& Grof (3) published their modifications which are still in use today. As early as 1939. Engel (4) tried to solve the problems of interference by haemoglobin when bilirubin was measured in haemolytic sera. Assuming that bilirubin was destroyed by oxidation by oxyhaemoglobin, he proposed the conversion of haemoglobin to $\mathrm{CO}$-haemoglobin to prevent destruction of bilirubin. Since then, several mechanisms of action of haemoglobin have been proposed (tab. 1), including interference of haemoglobin with the diazo reaction, inappropiate blank formation and peroxidation of bilirubin by haemoglobin. In addition, the introduction of the single reagent method using the preformed diazo compounds seemed to give an even higher degree of interference leading to intolerable results even at haemoglobin concentrations invisible to the naked eye (11). Therefore we reinvestigated this problem in more detail in a comparative study, applying most of the presently used modifications.

\section{Materials and Methods}

Preparation of samples

Nonhaemolytic sera $(\mathrm{Hb}$ below $0.2 \mathrm{~g} / \mathrm{l})$ with different total bilirubin concentrations were pooled and stored in the dark at $+4{ }^{\circ} \mathrm{C}$. Haemoglobin solution was freshly prepared from washed erythrocytes by haemolysis in distilled water, and diluted to a concentration of $10 \mathrm{~g} / \mathrm{l}$. From this solution different dilutions were prepared with pool sera to give final haemoglobin concentrations of 0.25 to $5 \mathrm{~g} / \mathrm{l}$. Haemoglobin concentration was determined by the method of Van Kampen \& Zijlstra (12))

Bilirubin determination

Total (conjugated and unconjugated) bilirubin was measured by seven different procedures listed in table 2 , according to the instructions of the suppliers. Table 2 summarizes reagents, wavelengths and photometers used. Most of these procedures were one reagent methods. except the Jendrassik-Grof modifications (3).
Tab. 1. Proposed mechanisms of interaction.

1. Oxidation of bilirubin by peroxidative action of haemoglobin (Engel (4), Shull et al. (5))

2. Haemoglobin interfers with the diazo reaction (Novros et al. (6))

3. Blank value too high in the presence of hadmoglobin $(7,8,9)$

4. Fading of diazo-bilirubin colour caused by haemoglobin (10)

\section{Other reagents}

All basic chemicals were of analytical grade from Merck, Darmstadt. Superoxide dismutase was supplied by Boehringer Mannheim, Germany; bilirubin-Versatol (Goedecke, Freiburg, Germany) was used as control material.

\section{Results}

In preliminary observations we found that the degree of interference by haemoglobin in the diazo determination of bilirubin was dependent on the modification used (11). This can be seen from figure 1 , where 7 different procedures presently available are compared. When increasing amounts of haemoglobin were added to sera containing $71 \pm 18 \mu \mathrm{mol} / \mathrm{l}$ (mean \pm SD of 8 sera) bilirubin, the percentage deviation was largely dependent on the method used. The smallest interference was observed with the Jendrassik-Grof procedures and with direct photometry used in neonatal sera. With these methods interference did not exceed $20 \%$, even at high haemoglobin concentrations. The single reagent methods, however, using preformed diazonium salts, gave much higher deviations. Interestingly; this was not the case with the dual wavelength procedure, which uses $650 \mathrm{~nm}$ as the reference wavelength instead of a blank sample. We therefore compared the 2,5-dichlorophenyldiazonium method with a one-wavelength and a two-wavelength procedure (method 5 a and $b$ ). As can be seen, haemoglobin interference was much less with the dual wavelength method

Tab. 2. Bilirubin assays studied

\begin{tabular}{|c|c|c|c|}
\hline Method & Reagent from & $\begin{array}{l}\text { Wavelength } \\
(\mathrm{nm})\end{array}$ & Photometer \\
\hline 1. Jendrassik-Grof (+Fehling) (3) & Merck & 578 & Eppendorf \\
\hline 2. Jendrassik-Grof, Nosslin (3) & Goedecke & 578 & Eppendorf \\
\hline 3. Nitrophenyldiazonium (13) & Dupont, T-Bil. & $540 / 600$ & Dupont-ACA \\
\hline 4. Direct reading method (14) & Dupont, N-Bil. & $49 \cdot 2 / 540$ & Dupont-ACA \\
\hline 5. 2,5-Dichlorophenyldiazonium, detergent (15) & Boehringer, $\mathrm{M}$. & $\begin{array}{l}\text { a) } 546 \\
\text { b) } 540 / 650\end{array}$ & $\begin{array}{l}\text { Eppendorf } \\
\text { Abbott } 100\end{array}$ \\
\hline 6. 2,4-Dichloraniline (16) & Boehringer, I. & 546 & Eppendorf \\
\hline 7. 2,5-Dichlorophenyldiazonium (17) & Behring & 546 & Eppendorf \\
\hline
\end{tabular}


(5b). Above $2.5 \mathrm{~g} / 1$ of haemoglobin however, an increase in apparent bilirubin values was observed.

From these observations we concluded that changing the reference wavelengths would probably help in excluding haemoglobin interference. However, this turned out to be misleading, since interaction of haemoglobin depended not only on the haemoglobin but also on the bilirubin concentrations. As can be seen from figure 2, the blank was increased by haemoglobin (fig. 2b), but largely independent of bilirubin concentrations. In contrast, the absorbance of the sample increased with haemoglobin at low bilirubin concentrations, was unchanged at slightly elevated and decreased at high bilirubin concentrations (fig. $2 \mathrm{a}$ ). This led to a bilirubin-dependent fall in (sample-blank) values as calculated in figure $2 \mathrm{c}$. Therefore the omission of the blank or the use of the reference wavelength does not help to eliminate interference at all bilirubin concentrations. It is only between 50 and $75 \mu \mathrm{mol} / \mathrm{l}$ bilirubin that the increase in blank absorbance is largely cancelled by the decrease in diazo colour, thus leading to an apparently unchanged bilirubin concentration when the blank is not subtracted. It seemed therefore inappropiate to generally propose two wavelength methods in order to eliminate the haemoglobin interference. This is especially true when $600 \mathrm{~nm}$ is used as the reference wavelength (tab. 1, method 3).

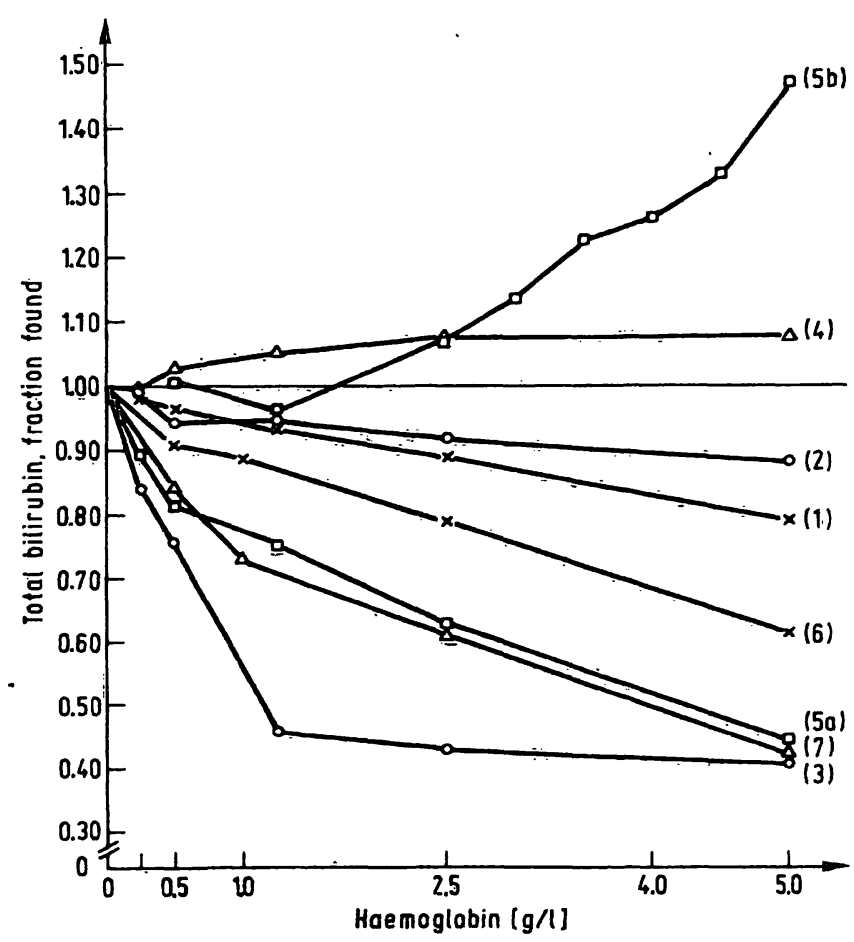

Fig. 1. Effect of haemoglobin concentration on total bilirubin measured with 8 different procedures.

The numbers in brackets give the methods used listed in table 2. Results are given as fraction of the control value in the absence of haemoglobin $(1.00=71.0 \pm 18.1 \mu \mathrm{mol} / \mathrm{l}$ $=4.15 \pm 1.06 \mathrm{mg} / \mathrm{dl}$ total bilirubin).
In addition to the variability of haemoglobin interaction in the different methods, the effect of haemoglobin was also variable in the same procedure. This was because the diazo colour in haemoglobin-containing samples changed with time, but was stable in uncontaminated samples. This time-dependent behaviour was further studied by addition of haemoglobin to samples already reacted with the diazo compound. As can be seen in figure 3, haemoglobin leads to a time dependent fading of colour in the sample. Although the same phenomenon occurs in the blank, it appeared much more slowly and exhibited a time lag of about $10-15$ minutes. From these experiments, it can be suggested that haemoglobin leads to a destruction of the diazo-bilirubin colour formed during incubation.

To further elucidate the mechanism of action of haemoglobin we followed the suggestion of Engel (4) that only oxyhaemoglobin interferes with the diazo reaction. In fact when haemoglobin was converted to haemiglobin less interference was observed (not shown) (8).

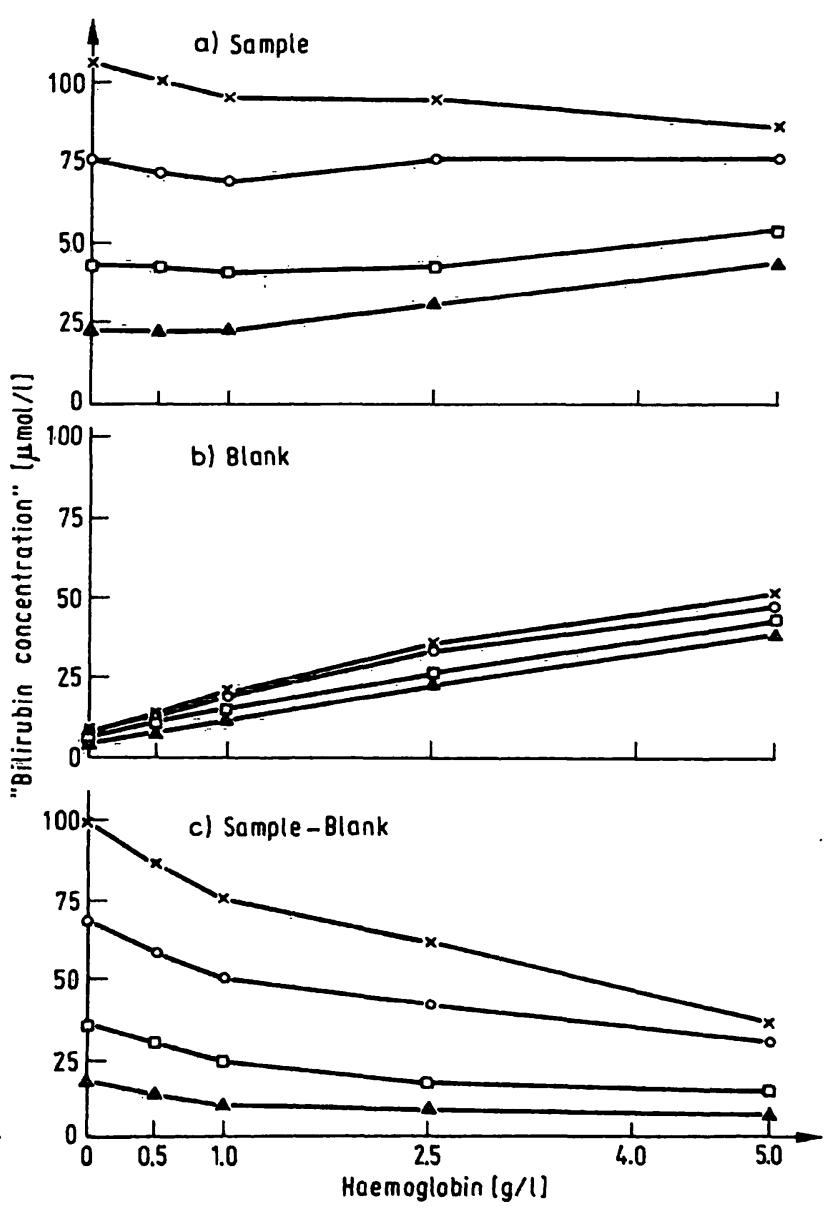

Fig. 2. Haemoglobin and bilirubin dependence of sample and blank absorbance in the 2,5-dichlorophenyldiazonium procedure (17). Sample (a) and blank (b) values were measured at $546 \mathrm{~nm}$ in an Eppendorf photometer against distilled water. The difference between sample and blank (c) gives the apparent bilirubin value. 


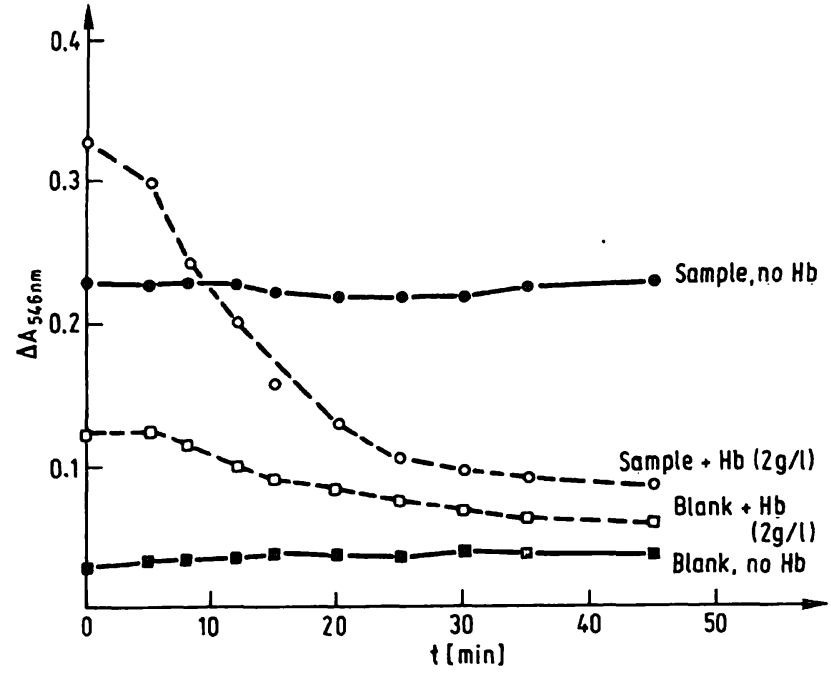

Fig. 3. Time dependence of the effect of haemoglobin on the diazo-bilirubin colour. Bilirubin was measured according to 1 . c. (17) in the sample containing $65 \mu \mathrm{mol} / 1$ of bilirubin.

This result agrees with the observation that storage of haemolytic sera for up to 16 days led to a gradual disappearance of interfering effects of haemoglobin (fig. 4). In parallel with this change, the colour of the haemolytic sera changed to that of haemiglobin. The sera without haemoglobin did not show this effect. Following the suggestion of previous authors, that oxyhaemoglobin is the interfering substance $(4,8)$, either free oxygen radicals, or hydrogen peroxide could be the destructive agent. Surprisingly, $\mathrm{H}_{2} \mathrm{O}_{2}$, when added to non-haemolytic sera in concentra-

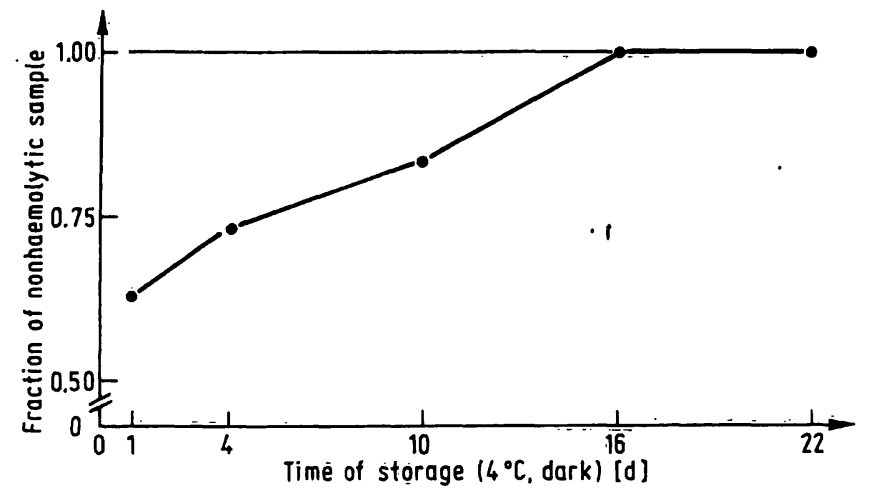

Fig. 4. Effect of sample storage on haemoglobin bilirubin interaction. Pool serum containing $58 \mu \mathrm{mol} / \mathrm{l}$ bilirubin and $2.5 \mathrm{~g} / \mathrm{l}$ haemoglobin was stored over 22 days together with the control sample without haemoglobin; method 7. of tab. 2 was used and the result given as fraction of the nonhaemolytic sample.

tions of up to $16 \mathrm{mmol} / \mathrm{/} \mathrm{had} \mathrm{no} \mathrm{effect} \mathrm{on} \mathrm{diazo-bili-}$ rubin determination (tab. 3). It potentiated however, the interfering effect of haemoglobin (fig. 5). These results indicated that $\mathrm{H}_{2} \mathrm{O}_{2}$ led to destruction of the diazo compound only in the presence of the haem iron.

To further study whether free oxygen radicals were involved, well known scavengers of these reagents were added, together with haemoglobin; to bilirubin-containing samples.

Of the added substances summarized in table 3, ascorbate, which was used successfully in the Jendras-

Tab. 3. Effect of chemical substances on bilirubin/haemoglobin interaction in the 2,5-dichlorophenyldiazonium procedure. Percent inhibition of haemoglobin-containing bilirubin samples with the chemical compound and distilled water were compared: Pooled serum samples were tested in the absence and presence of haemoglobin added at a concentration of $5 \mathrm{~g} /$ as described in the methods. All tests were performed with the 2,5-dichlorophenyldiazonium-method. The effects of the added substances is given in percent of the control in the absence of haemoglobin to exclude direct interaction of the substance with the diazo procedure. Effect of haemoglobin is given as percent inhibition in the absence and presence of added substance.

\begin{tabular}{|c|c|c|c|c|c|}
\hline Substance added & $\begin{array}{l}\text { Final concentration } \\
(\mathrm{mmol} / \mathrm{l})\end{array}$ & $\begin{array}{l}\text { Bilirubin concen- } \\
\text { tration in the } \\
\text { absence of haemo- } \\
\text { globin and added } \\
\text { substance } \\
(\mu \mathrm{mol} / \mathrm{l})\end{array}$ & $\begin{array}{l}\text { Change by chemical } \\
\text { compound in the } \\
\text { absence of } \\
\text { haemoglobin } \\
(\%)\end{array}$ & $\begin{array}{l}\text { Inhibition by } \\
\text { haemoglobin in the } \\
\text { absence of added } \\
\text { substance } \\
(\%)\end{array}$ & $\begin{array}{l}\text { Inhibition by } \\
\text { haemoglobin in the } \\
\text { presence of added } \\
\text { substance } \\
(\%)\end{array}$ \\
\hline 1. Ascorbate & 2.0 & 76 & -72 & 41 & 48 \\
\hline 2. Mannitol & 1.9 & 102 & +2 & 66 & 5.2 \\
\hline 3. Pyrogallol & 2.8 & 58 & -9 & 75 & 16 \\
\hline 4. Catalase & 325 U per assay & 83 & +7 & 60 & 66 \\
\hline $\begin{array}{l}\text { 5. Superoxide } \\
\text { dismutase }\end{array}$ & $0.5 \mathrm{E}$ & 83 & +12 & 60 & 68 \\
\hline $\begin{array}{l}\text { 6. Catalase }+ \\
\text { superoxide } \\
\text { dismutase }\end{array}$ & $\begin{array}{c}325 \mathrm{U}+0.5 \mathrm{E} \\
\text { per assay }\end{array}$ & 83 & +4 & 60 & 75 \\
\hline 7. $\mathrm{H}_{2} \mathrm{O}_{2}$ & 16 & 67 & -2 & 41 & 86 \\
\hline $\begin{array}{l}\text { 8. Potassium iodide } \\
\text { Potassium iodide }\end{array}$ & $\begin{array}{l}4.4 \\
4.4\end{array}$ & $\begin{array}{l}64 \\
.65 \text { (3 weeks old) }\end{array}$ & $\begin{array}{l}-4 \\
+3\end{array}$ & $\begin{array}{l}38 \\
14\end{array}$ & $\begin{array}{r}11 \\
\therefore 2 \\
\end{array}$ \\
\hline
\end{tabular}




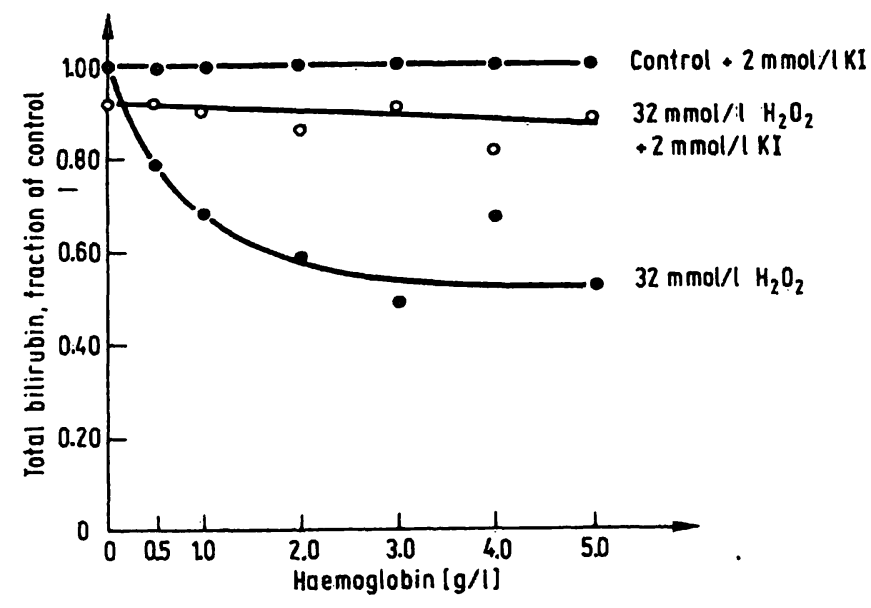

Fig. 5. The effect of $\mathrm{H}_{2} \mathrm{O}_{2}$ on the interaction of haemoglobin with the total bilirubin determination; $1.00=52 \mu \mathrm{mol} / \mathrm{l}$ at $0 \mathrm{~g} /$ $\mathrm{Hb} ; 16 \mu \mathrm{mol} / \mathrm{h}$ at $5 \mathrm{~g} / \mathrm{Hb}$. KI was at the final concentration of $2 \mathrm{mmol} / \mathrm{l}$ added shortly before the reagent.

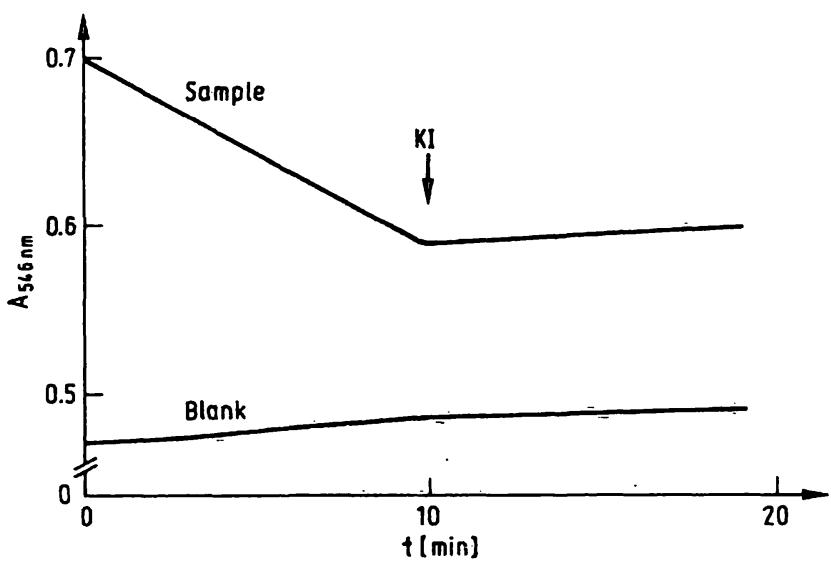

Fig. 6. Experimental conditions were as in figure 3, except that $\mathrm{KI}$ was added at the time indicated $(4.4 \mathrm{mmol} / \mathrm{l})$.

sik-Grof procedures (8), largely inhibited the reaction by itself in the 2,5-dichlorophenyldiazonium procedure, but had not effect on haemoglobin interference. Mannitol, a scavenger of OH-radicals likewise did not prevent the effect of haemoglobin. The same was true for superoxide dismutase and catalase, either alone or in combination. Pyrogallol however, another scavenger and redox system, prevented the interaction to some extent. The best effect was obtained with $\mathrm{KI}$ in concentrations above $1 \mathrm{mmol} / \mathrm{l}$, which had no effect on the method but prevented haemoglobin interference nearly completely. When added to different types of experiments, like those shown in figures 2,3 and $5, \mathrm{KI}$ stopped the fading of diazo-bilirubin colour instantaneously (fig. 6) and prevented the effect of $\mathrm{H}_{2} \mathrm{O}_{2}$ and diazo-bilirubin formation in the presence of haemoglobin (fig. 5). When added to samples before the assay, haemoglobin interference was completely eliminated up to the highest concentration studied
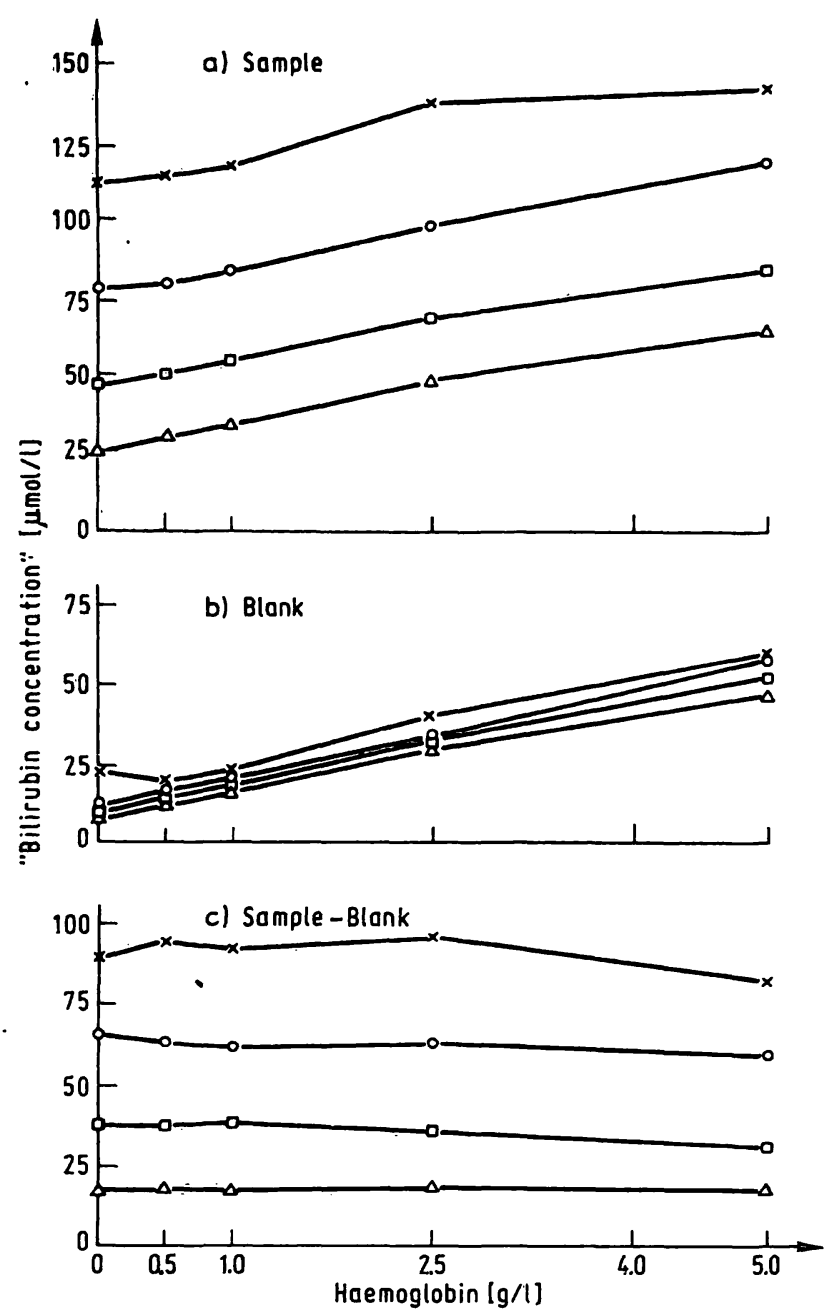

Fig. 7. Effect of $4.4 \mathrm{mmol} / 1 \mathrm{KI}$ on haemoglobin interference in the 2,5-dichlorophenyldiazonium procedure for total bilirubin. $\mathrm{KI}$ was added shortly before addition of the reagent to the sample and the blank (cf. fig. 2).

(fig. 7). Sample absorbance now increased in parallel with the blank absorbance, thus leading to an unchanged difference. Unfortunately, addition of $\mathrm{KI}$ to different diazo reagents led to a variable time dependent formation of iodine which itself interfered with the bilirubin determination. Therefore $\mathrm{KI}$ was added at a final concentration of $4 \mathrm{mmol} / \mathrm{l}$ shortly before addition of diazo regent to the blank and sample to prevent haemoglobin interference in manual diazo procedures. Addition of iodide did not help in dual wavelength methods, because of the missing blank correction.

\section{Discussion}

Numerous studies on the interaction of haemoglobin with the diazo determination of bilirubin have been reviewed (7-9). In spite of this vast amount of literature, the quantitative aspects of different modifications have not been defined and the proposed 
mechanisms remain controversial (7). From the present studies it can be concluded that the degree of interaction not only depends on the amount of haemoglobin present, but also on the bilirubin content, the "age" of the sample, time of incubation, $\mathrm{pH}$ of reaction mixture (23), reference wavelength and diazonium salt used. These multiple factors make it difficult to predict the degree of interference with a given method and account for the multiplicity of possible explanations in the literature.

Engel has already postulated (4) that haemoglobin destroys bilirubin by its peroxidative action. Although this mechanism has been confirmed in several studies $(5,7)$ the diazo-negative products of bilirubin oxidation have not been identified (19). For several reasons, this idea does not explain the observed interference in the present study: in spite of prolonged incubation of haemolytic samples, bilirubin was stable over 14 days (fig. 4). Moreover, haemoglobin reacts when added after completion of the diazo-bilirubin reaction (fig. 3); therefore the oxidation of bilirubin, although not excluded, seems to be of minor relevance to the present observation. The results point more to an interaction of haemoglobin with the diazo-bilirubin colour. The question is whether interference appears at the diazo-bilirubin formation step, or whether haemoglobin destroys the diazo-bilirubin colour. Both mechanisms would lead to the same results, namely a loss of reaction product. Results shown in figure 3 clearly demonstrate that the reaction product is destroyed by interaction with haemoglobin. A similar result was obtained by Michaelsson in 1961 (10) and more recently by Homsher et al. (20). In contrast, Novros (6) excluded this mechanism, because haemoglobin, when added after diazo-bilirubin formation, did not reduce the apparent bilirubin value. This may be caused by the fact that the time after haemoglobin addition was not sufficient to destroy the diazo-product. According to our observations, at least $10 \mathrm{~min}$ utes are needed for the observed decrease in diazobilirubin colour. On the other hand, the included detergent may have stabilized the diazo colour. Since most diazo procedures need a sample blank and interference is largely reduced when this blank is omitted (fig. 1, method 5b and fig. 2a) inappropiate blank formation was most often proposed as the reason for lower bilirubin values $(7,8,9)$. In fact, omission of the blank leads to a stable absorbance at 50$75 \mu \mathrm{mol} / \mathrm{l}$ bilirubin. Likewise, inclusion of a reference wavelength eliminates the interference up to a haemoglobin concentration of $2.5 \mathrm{~g} / 1$ (fig. 1, 5 a versus $5 \mathrm{~b}$ ). Similar observations have recently been published in an abstract by Portnoy et al. (21).
Homsher et al. concluded from spectrophotometric analysis of the different reaction mixtures, that haemoglobin interaction with unreacted bilirubin was stronger in the blank than in the sample, thus leading to a relatively high blank (6). A similar conclusion was drawn by Shull et al. (8), suggesting that haemiglobin formation in the sample was higher than in the blank, leading to a relatively higher absorption of the blank sample. The results obtained with the preformed diazo salts (fig. 2 ) clearly show that although blank absorption is linearly dependent on haemoglobin concentration it cannot be the cause of the decrease in bilirubin value. The lack of the parallel increase in the sample procedure seems to be due rather to a decrease in the formation of the diazo colour. This explains why omission of the blank and choice of reference wavelength does not exclude haemoglobin interference at all haemoglobin and bilirubin concentrations. If the same wavelength is used for the blank formation as for the sample, bilirubin concentrations above $75 \mu \mathrm{mol} / /$ give decreased results upon omission of the blank whereas at low bilirubin concentrations the result is apparently too high (fig. $2 \mathrm{a}$ ). On the other hand, when $650 \mathrm{~nm}$ is chosen as the reference wavelength, interference is much less, but cannot be completely neglected. Moreover, a reference wavelength of $600 \mathrm{~nm}$ (method 3 in tab. 2) seems to increase rather than decrease the degree of interference (method 3 in fig. 1). In conclusion, although helpful in some instances, haemoglobin interference with the diazo-bilirubin formation cannot be completely avoided by appropiate blanking.

Regarding the mechanism of haemoglobin interaction, the observed fading of the diazo-bilirubin colour, already observed by Michaelsson (10), seems to be of special interest. Since oxyhaemoglobin was found to be the interfering haemoglobin species, the oxidation of the diazo-bilirubin colour seems to be the most likely mechanism. Oxyhaemoglobin can either act by its catalytic peroxidative action or by the formation of superoxide radicals during autoxidation (22). During haemoglobin autoxidation, superoxide radicals react with the haem iron to form haemiglobin (22), which has been shown to have no influence on diazo-bilirubin. On the other hand, the peroxidative action of haemoglobin would need $\mathrm{H}_{2} \mathrm{O}_{2}$ as substrate, which has likewise been shown to be formed from oxyhaemoglobin. The observation that $\mathrm{H}_{2} \mathrm{O}_{2}$ potentiated the effect of haemoglobin on the diazocoupling procedure also points to a role of this peroxide in the observed interference. Since $\mathrm{H}_{2} \mathrm{O}_{2}$ had no effect in the absence. of haemoglobin, haemoglobin seems to catalyse the ifading of the dia- 
zo-bilirubin colour. Other free oxygen radicals seem much less involved in the observed interfering action, since mannitol, a scavenger of $\mathrm{OH}$-radicals, did not prevent interference. Our observation that haemiglobin did not react and resulted in a stable diazobilirubin colour also points to the role of active oxygen species in the interfering action.

Our results indicate that haemoglobin acts by a $2-$ step mechanism. Oxyhaemoglobin may lead to a formation of $\mathrm{H}_{2} \mathrm{O}_{2}$, which, by the peroxidative function of the haem iron, would result in a peroxidation product of the diazo-bilirubin colour, leading to a decrease in apparent absorbance in the sample (fig. 8). A similar mechanism was proposed by Shull et al. (5). In contrast to his conclusion however, our results indicate that $\mathrm{H}_{2} \mathrm{O}_{2}$ did not prevent diazo-bilirubin colour formation but rather destroyed preformed reaction products.

The protective effect of $\mathrm{KI}$ may be due to its dual potential. On the one hand, it would destroy $\mathrm{H}_{2} \mathrm{O}_{2}$ formed during autoxidation of haemoglobin, and on the other hand stabilize the diazo-bilirubin colour against the peroxidative action of the haem iron. Unfortunately, this preservative cannot be included in

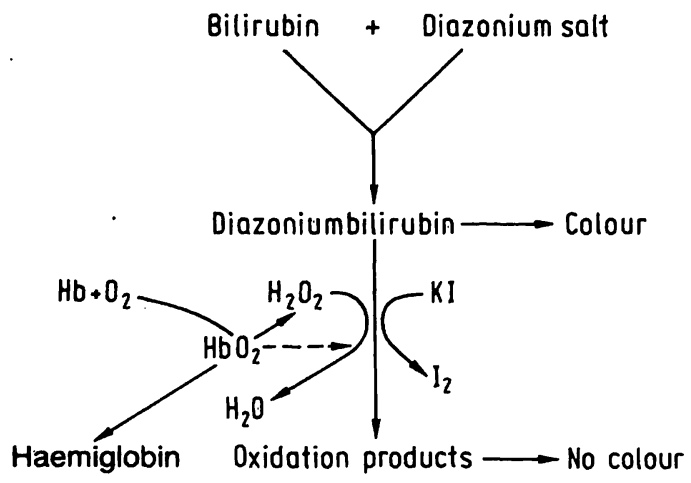

Fig. 8. Proposed mechanism of interference of haemoglobin with the diazo reaction of bilirubin.

$\mathrm{HbO}_{2}$ acts as generator of $\mathrm{H}_{2} \mathrm{O}_{2}(\rightarrow)$ and as catalyst $(---\rightarrow)$.

the reagents because of variant impurities which lead to $\mathbf{I}_{\mathbf{2}}$-formation upon storage. This $\mathbf{I}_{2}$ again interferes with all procedures using a reference wavelength and must be subtracted with aid of a blank measured at the same wavelength as the sample. Therefore, KI cannot be used in procedures that use blank determination in the sample by reference wavelengths. When added shortly before the reaction, bilirubin can be determined accurately, even in the presence of haemoglobin concentrations up to $5 \mathrm{~g} / \mathrm{l}$.

\section{References}

1. Van den Bergh, A. A. H. \& Schnapper, J. (1913) Dtsch. Arch. Klin. Med. 110, 540-561.

2. Malloy, H. T. \& Evelyn, K. A. (1937) J. Biol. Chem. 119. $481-490$.

3. Jendrassik, L. \& Grof, P. (1938) Biochem. Z. 297, 81-89.

4. Engel, M. (1939) Hoppe Seylers Z. Physiol. Chem. 259, 7582 .

5. Shull, B. C., Lees, H. \& Li, P. K. (1980) Clin. Chem. 26, 2225.

6. Novros, J. S., Koch, T. R. \& Knoblock, E. C. (1979) Clin. Chem. 25, 1891-1899.

7. Homsher, R., Wesenberg. J. C., Baginski, E. S. \& Zak, B. (1979) Microchemical J. 24, 526-535.

8. Shull, B. C.. Lees, H. \& Li, P. K. (1980) Clin. Chem. 26, 2629.

9. Michaelsson, M., Nosslin, D. \& Sjolin, S. (1965) Pediatrics 35, 925-931.

10. Michaelsson, M., (1961) Scand: J. Clin. Lab. Invest. 13, Suppl. 56.

11. Woerd-de Lange, J. A. van der, Schleicher, E., Guder, W. G. \& Wieland, O. H. (1981) J. Clin. Chem. Clin. Biochem. 19, 213-246.

12. Van Kampen, E. J., Zijlstra, W. G. (1965) Adv. Clin. Chem. $8,141-187$.

13. Chemistry instruction Manual (1978) Total Bilirubin Du Pont.

14. Blijenberg, B. G. \& Leijnse, B. (1979) J. Clin. Chem. Clin. Biochem. 17, 303-308.

15. Wahlefeld, A. W., Herz, G. \& Bernt, E. (1972) Scand. J. Clin. Lab. Invest. 29, 126, 11-12.

16. Hillmann, G: \& Beyer, G. (1967) Z. Klin. Chem. 5, 92-93.

17. Weigl, E., Bach. H. \& Krieg, D. (1975) Med. Klinik 70. 664-669.

18. Henry, R. J., Cannon, D. C. \& Winkelman, J. W. (1974) Clinical Chemistry, Principles and Technics, Second Edition 1058.

19. Brodersen, R. \& Bartels, P. (1969) Eur. J. Biochem. IO. 468-473.

20. Homsher, R., Chu, J. W. \& Zak, B. (1981) Clin. Chem. 27. 1067-1067.

21. Portnoy, A. L., Harrigan, T., Likeas, P., Narayanan, S. (1981) Clin. Chem. 27, 1037.

22. Misra, H. P. \& Fridovich, I. (1972) J. Biol. Chem. 247. 6960-6962.

23. Ceriotti. G., Quality control in clinical chemistry (1975) April 23-25, 3-10.

Jannic A. van der Woerd-de Lange Institut für Klinische Chemie

Städt. Krankenhaus

München-Schwabing

Kölner Platz 1

D-8000 München 40 
